J. Lake Sci. (湖泊科学) , 2011, 23(5): 806-812

http: //www. jlakes.org. E-mail: jlakes@niglas.ac.cn

(C) 2011 by Journal of Lake Sciences

\title{
新疆布伦托海轮虫群落结构及其与环境因子的关系*
}

\author{
杨丽 丽 $^{1}$, 周小王 ${ }^{1}$, 刘其根 ${ }^{* * *}$, 胡忠军 ${ }^{1}$, 王钰博 ${ }^{1}$, 江 敏 $^{1}$, 刘 军 $^{2}$, 李周永 ${ }^{2}$, 郝志才 ${ }^{2}$, 沈建忠 ${ }^{3}$ \\ ( $1:$ 上海海洋大学农业部水产种质资源与利用重点开放实验室, 上海 201306) \\ $(2$ : 新疆维吾尔自治区福海县水产局,福海 836400$)$ \\ (3:华中农业大学水产学院,武汉 430070)
}

\begin{abstract}
摘 要: 本文于 2006 年秋至 2008 年夏, 对新疆布伦托海轮虫的群落组成、时空分布及其与环境因子的相关性进行了系 统的调查. 结果表明, 本次调查采集到布伦托海轮虫 30 种, 主要优势种有针簇多枝轮虫 (Polyarthra trigla)、长三肢轮虫 (Filina longiseta)、奇异六腕轮虫 (Hexarthra mira)、方形臂尾轮虫 (Brachionus quadridentatus)、矩形龟甲轮虫 (Keratella quadrata) 和螺形龟甲轮虫 ( $K$. cochlearis). 种类分布格局为: 大湖多于湖湾 (如骆驼脖子、73 $\mathrm{km}$ 小海子和中海子), 湖心区 高于沿岸区; 但其密度和生物量却在骆驼脖子中达到最大, 而湖心区又高于沿岸区; 季节变化格局为: 在 2006 年秋季和 2007 年夏季达到高峰,2006 年冬季达最低; CCA 分析表明, 温度、溶解氧和浮游植物生物量对针簇多肢轮虫等影响较大, 透明度、Chl. a、枝角类生物量对轮虫分布也有一定影响; 在季节变化中浮游植物生物量与轮虫生物量呈正相关性, 显示了 其对轮虫生物量影响的主导作用; 在空间变化中, 起竞争作用的枝角类和起捕食作用的剑水蚤生物量与轮虫生物量呈负 相关性,表明其对轮虫的下行效应起着主导作用.
\end{abstract}

关键词: 布伦托海;轮虫; 时空分布;生物入侵;典范对应分析

\section{Community structure of rotifer and its relation to environment factors in Lake Buluntuohai}

YANG Lili ${ }^{1}$, ZHOU Xiaoyu ${ }^{1}$, LIU Qigen ${ }^{1}$, HU Zhongjun ${ }^{1}$, WANG Yubo ${ }^{1}$, JIANG Min ${ }^{1}$, LIU Jun, LI Zhouyong $^{2}$, HAO Zhicai ${ }^{2}$ \& SHEN Jianzhong ${ }^{3}$

(1: Key Laboratory of Aquatic Genetic Resources and Utilization (Ministry of Agriculture), Shanghai Ocean University, Shanghai 201306, P. R. China)

(2: Aquatic Bureau of Fuhai of Xinjiang Uygur Autonomous Region, Fuhai 836400, P. R. China)

(3: College of Fisheries, Huazhong Agricultural University, Wuhan 430070, P. R. China)

Abstract: The spatial and temporal distribution of rotifers, together with various environmental parameters, in Lake Buluntuohai were investigated from autumn of 2006 to summer of 2008, and the relationship between the distribution pattern of rotifers and the environmental parameters was analyzed accordingly. The results showed that 30 taxa were recorded in total and the dominant species included Polyarthra trigla, Filina longiseta, Hexarthra mira, Brachionus quadridentatus, Keratella quadrata and K. cochlearis. Both the rotifer density and biomass displayed a clear seasonal pattern with two peaks in autumn of 2006 and in summer of 2007. The spatial dynamics of rotifers during the two years were characterized by two distinctive features: The maximums of rotifer density and biomass were recorded in one of the bays in the lake, called Luotuobozi, and the biggest number of species was identified in main water body, the open water in the lake. The density and biomass of rotifer were found to be in a decreasing order from sampling sites in the open water to eastern littoral zone and to western littoral zone. CCA results also showed that certain species, such as Polyarthra trigla were associated with water temperature, dissolved oxygen and the biomass of phytoplankton. The rotifer biomass in the lake was mainly determined by phytoplankton seasonally, while the biomass presents a negative relation with potential predators (cyclopida) and competitors (cladocera) that both dominated the rotifer biomass.

Keywords: Lake Buluntuohai; rotifer; temporal and spatial distributions; biological invasion; canonical correspondence analysis

* 新疆福海县人民政府和上海市重点学科项目 (Y1101) 资助. 2010-11-30 收稿;2011-03-03 收修改稿. 杨丽丽, 女,1986 年生, 硕士研究生; E-mail: yanglilytjac@126. com.

** 通讯作者;E-mail:qgliu@ shou. edu.cn. 
轮虫是淡水浮游动物的重要组成部分, 其作为捕食者和被捕食者, 不但在经典食物网中起着连接藻类 与高营养级的作用, 而且还是连接微食物环与经典食物网的重要中间环节, 因此在水体的物质循环和能量 流动过程中发挥着十分重要的作用. 此外, 轮虫还是水体中重要的指示生物类群, 在水污染评价和水体营养 评价方面受到了国内外学者的广泛重视 ${ }^{[1-3]}$. 而同样重要但却较少受到关注的是, 轮虫还是很多鱼类幼鱼的 适口或开口饵料, 因此轮虫数量的变动还可能会影响到这些鱼类幼鱼的成活率和天然鱼类资源的后代补 充, 从而对鱼类群落结构产生影响. 特别是外来食浮游动物鱼类的引种所引起的对湖泊土著鱼类的影响的 内在的机制是否涉及轮虫这一中间环节值得关注.

布伦托海是新疆北部地区的大型内陆湖, 它与吉力湖共同构成了我国十大淡水湖之一的乌伦古湖, 是 新疆重要的渔业基地, 同时在维护地区生态平衡方面也发挥着重要作用. 然而, 有关乌伦古湖布伦托海的相 关生态学历史研究资料较少, 而对其浮游动物包括轮虫的研究更少见. 陈伟民等曾于 1986 年夏季对整个乌 伦古湖 (包括布伦托海) 的浮游生物 (包括轮虫) 开展了初步的调查 ${ }^{[4]}$, 任慕莲、姜作发等曾于 $1986-1987$ 年 间对乌伦古湖的子湖吉力湖进行了较为系统的调查, 其中包括对轮虫调查的相关资料 ${ }^{[5]}$, 而叶尚明等则于 $2001-2002$ 年对布伦托海的水生生物资源进行了再次调查 ${ }^{[6]}$. 由此可见, 有关布伦托海或整个乌伦古湖的 历史研究资料是零星和不系统的, 而且自陈伟民等的初次调查至今, 布伦托海的生态系统已发生了很大的 变化, 主要是在 1991 年前后食浮游动物鱼类池沼公鱼被引入该湖, 并很快成为优势种, 其产量最高时曾达 $1800 \mathrm{t}$ 以上, 至今仍在湖泊鱼产量中占到 $40 \%$ 以上, 这种外来食浮游动物鱼类占优势的情况必然会影响到 轮虫群落组成及其时空变动.

为此, 本文于 2006 至 2008 年分季度对布伦托海的轮虫开展调查, 通过分析轮虫的群落结构、生物量和 物种多样性变化及其水质状况, 为布伦托海开发、利用及其环境演化, 以及了解池沼公鱼引种对湖泊的影响 等提供一定的参考依据.

\section{1 材料与方法}

\section{1 研究地概况}

乌伦古湖布伦托海 $\left(46^{\circ} 51^{\prime}-47^{\circ} 25^{\prime} \mathrm{N}, 87^{\circ} 01^{\prime}-87^{\circ} 35^{\prime} \mathrm{E}\right)$ 位于我国西北地区准噶尔盆地北部、新疆维吾 尔自治区福海县境内, 面积 $745 \mathrm{~km}^{2}$, 平均水深 $8 \mathrm{~m}$, $2006-2007$ 年总氮年平均值为 $0.856 \pm 0.205 \mathrm{mg} / \mathrm{L}$, 总磷年平均值为 $0.028 \pm 0.033 \mathrm{mg} / \mathrm{L}$, 叶绿素 $\mathrm{a}$ 年平 均值为 $3.59 \pm 18.34 \mathrm{mg} / \mathrm{m}^{3[7]}$, 属微咸水湖泊, 是北 疆最大的内陆封闭型湖泊.

\section{2 样点设置与方法}

根据地表水监测技术规范 $($ KI/T $91-2002)$ 的有 关规定 ${ }^{[8]}$, 于布伦托海设置 25 个采样点, 从 2006 年 11 月至 2008 年 7 月按季度采样. 采样点分布如图 1 所示. 轮虫定性定量的样品采集、记数、种类鉴定均 按《淡水浮游生物研究方法》、《中国淡水轮虫志》等 资料进行 ${ }^{[9-12]}$. 根据地表水环境质量标准推荐的方 法, 测定各水样的透明度 (SD)、溶解氧 (DO)、叶绿素 $\mathrm{a}(\mathrm{Chl} . \mathrm{a})$ 、总磷 $(\mathrm{TP})$ 、总氮 $(\mathrm{TN})$ 和高锰酸盐指数 $\left(\mathrm{COD}_{\mathrm{Mn}}\right)$ 等 ${ }^{[8,13-14]}$.

\section{3 数据处理}

优势度 $Y^{[15]}>0.02$ 为优势种. $Y=N_{i} \times f_{i} / N$, 其 中, $N_{i}$ 为第 $i$ 种密度, $N$ 为该类群总密度, $f_{i}$ 为第 $i$ 种 在一年中出现的月份频率. 用方差分析 (ANOVA) 来 分析季节和水体中轮虫生物量的区别, 轮虫物种与

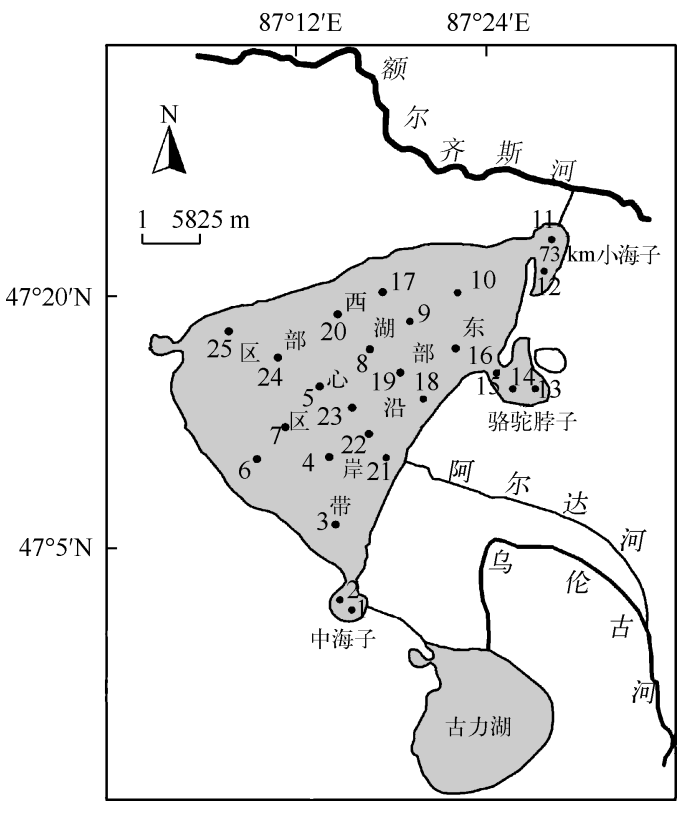

图 1 布伦托海采样点分布图

Fig. 1 Sample stations in Lake Buluntuohai 
环境因子的关系应用 CANOCO 4.0 进行典范对应分析 (CCA).

\section{2 结果}

\section{1 轮虫种类组成及其空间分布}

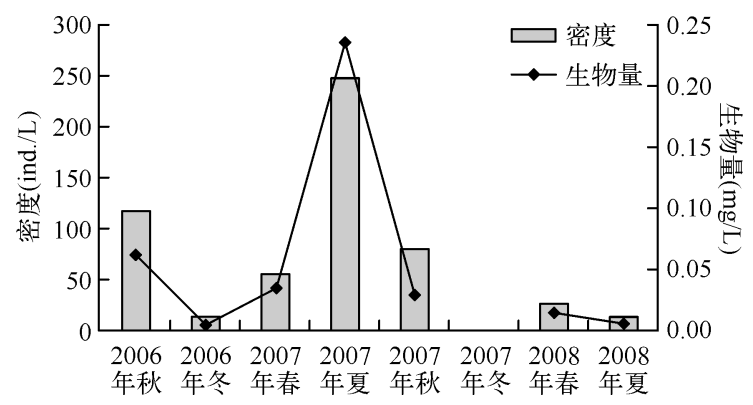

图 2 新疆布伦托海轮虫密度和生物量的季节变化 (2007 年冬季水样在托运过程中损坏导致数据缺失)

Fig. 2 Seasonal variation in density and biomass of rotifer in Lake Buluntuohai
本次调查共发现轮虫 17 属 30 种. 根据优势 度, 布伦托海的优势种有针簇多肢轮虫 (Polyarthra trigla)、长三肢轮虫 (Filina longiseta) 、奇异 六腕轮虫 (Hexarthra mira) 、方形臂尾轮虫 (Brachionus quadridentatus)、矩形龟甲轮虫 (Keratella quadrata) 和螺形龟甲轮虫 ( $K$. cochlearis).

布伦托海由大湖及三个湖湾 (中海子、骆驼 脖子和 $73 \mathrm{~km}$ 小海子) 四部分水域组成, 根据对 不同水域轮虫种类组成的分析可知, 大湖区轮虫 种类最多, 达 25 种, 其次为 $73 \mathrm{~km}$ 小海子, 达 16 种, 最少的是中海子, 12 种. 而从布伦托海的大 湖区来看, 由于营养盐补给主要来源于东北部人 湖水流和东部面源输人, 因此本研究又对布伦托 海的大湖区按照从东部沿岸带、湖心区和西部沿

岸区这样一个营养梯度对轮虫组成进行分析发现, 湖心区轮虫的种类最多, 达 21 种, 东部和西部沿岸带相 近, 分别为 15 种和 14 种.

\section{2 轮虫的密度和生物量}

布伦托海两年轮虫的密度和生物量相差很大, 2006 年秋至 2007 年夏, 轮虫的平均密度为 $108.2 \mathrm{ind}$. $/ \mathrm{L}$, 平 均生物量为 $0.085 \mathrm{mg} / \mathrm{L} ; 2007$ 年夏至 2008 年夏, 轮虫的平均密度为 $40.0 \mathrm{ind}$. / L , 平均生物量为 $0.017 \mathrm{mg} / \mathrm{L}$.

2006 年秋至 2008 年夏, 布伦托海 8 个季节的轮虫密度和生物量在 2007 年夏季形成高峰, 密度为 247.6 ind. $/ \mathrm{L}$, 生物量为 $0.25 \mathrm{mg} / \mathrm{L}, 2006$ 年秋季和 2007 年秋季密度和生物量相差不大, 可见轮虫的高峰期 在夏秋季节. 冬季的密度和生物量都达到全年的最低值, 2006 年冬季密度为 $6.8 \mathrm{ind} . / \mathrm{L}$, 生物量为 $0.0025 \mathrm{mg} / \mathrm{L}$ ( 图 2).

骆驼脖子点位轮虫的密度和生物量最高, 分别达 $114.4 、 0.051 \mathrm{mg} / \mathrm{L}, 73 \mathrm{~km}$ 小海子和大湖的密度和生物 量其次, 而中海子的密度和生物量最低, 分别为 $54.1 、 0.028 \mathrm{mg} / \mathrm{L}$ (图 3a). 湖心区的密度和生物量都最大, 分别为 $94.3 \mathrm{ind} . / \mathrm{L}$ 和 $0.051 \mathrm{mg} / \mathrm{L}$, 其次为西部区的密度和生物量, 分别为 $78.2 \mathrm{ind} . / \mathrm{L}$ 和 $0.0386 \mathrm{mg} / \mathrm{L}$, 东 部沿岸带轮虫的密度和生物量最小, 分别为 $67.1 \mathrm{ind} . / \mathrm{L}$ 和 $0.032 \mathrm{mg} / \mathrm{L}$. 东部沿岸带, 湖心区和西部区轮虫 的种类的多少和密度和生物量的大小相一致 (图 $3 \mathrm{~b}$ ).
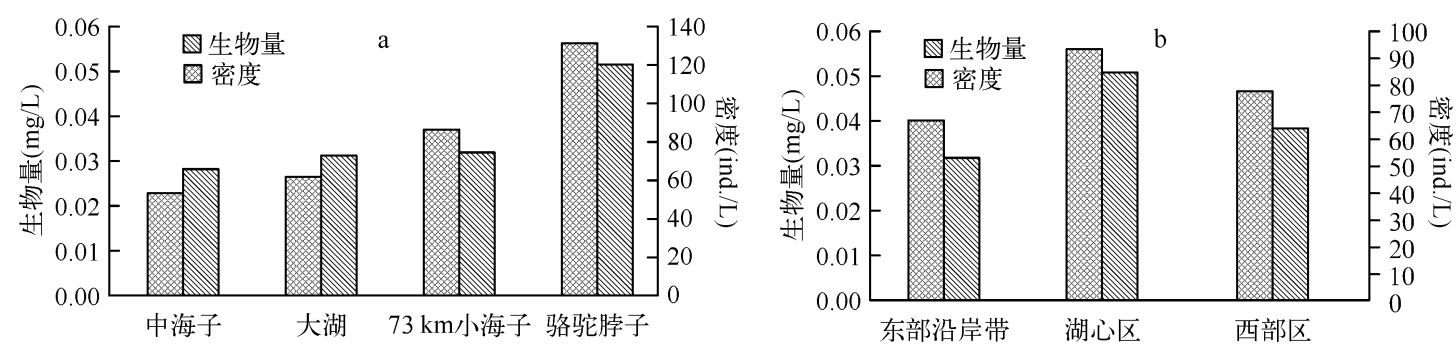

图 3 新疆布伦托海轮虫密度、生物量的水平空间变化

Fig. 3 Spatial variation in density and biomass of rotifer in Lake Buluntuohai 


\section{3 轮虫密度、生物量与环境因子的相关性分析}

2.3.1 轮虫物种与环境因子的 CCA 排序布伦托海 轮虫物种和环境因子的排序结果可以看出, 前两个 排序轴的特征值分别是 0.096 和 0.060 , 种类和环境 因子排序轴的相关系数高达 0.942 和 0.831 (图 4), 说明这 2 个排序轴的排序图能够反映乌伦古湖浮游 甲壳动物物种与环境因子间的关系. SD 和 Chl. a 含 量与第一轴的相关系数分别为 -0.5321 和 0.5757 . DO 、浮游植物生物量、温度和枝角类生物量与第二 轴的相关系数分别为 $0.4076 、 0.3302 、 0.5472$ 和 -0.6272 ; 同时物种扁平泡轮虫、针簇多肢轮虫、矩 形龟甲轮虫和奇异六腕轮虫与 DO、浮游植物生物 量、温度呈正相关, 长三肢轮虫与枝角类生物量呈 正相关. 方形臂尾轮虫与 SD 呈正相关, 而暗小异 尾轮虫和螺形龟甲轮虫与 Chl. a 含量呈正相关 (图4).

\subsection{2 轮虫生物量与生物因素的关系}

（1）与浮游植物生物量、Chl. a 的时空分布关 系:2006 年秋季轮虫生物量达到一个小高峰, 冬季 形成最低值, 随着温度的缓慢升高, 到 2007 年夏季 达到最高值. 而浮游植物的生物量与轮虫生物量趋 势相一致(图 5). 中海子、73 km小海子、大湖中 Chl. a 含量与轮虫生物量变化趋势相一致,而轮虫在骆驼 脖子的生物量最高, 而 Chl. a 含量相对较低 (图6).

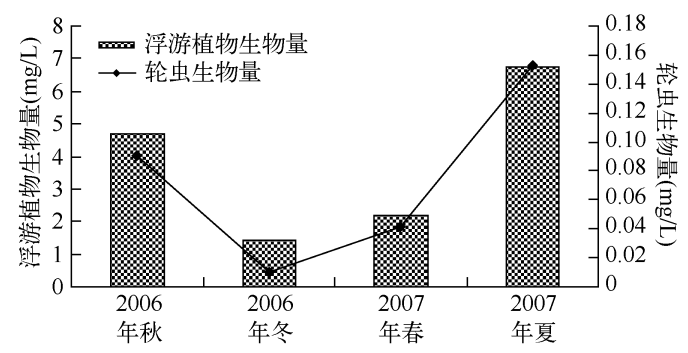

图 5 新疆布伦托海 2006 年秋至 2007 年夏浮游 植物生物量与轮虫生物量的关系

Fig. 5 The relationship between biomass of phytoplankton and rotifer from autumn 2006 to summer 2007

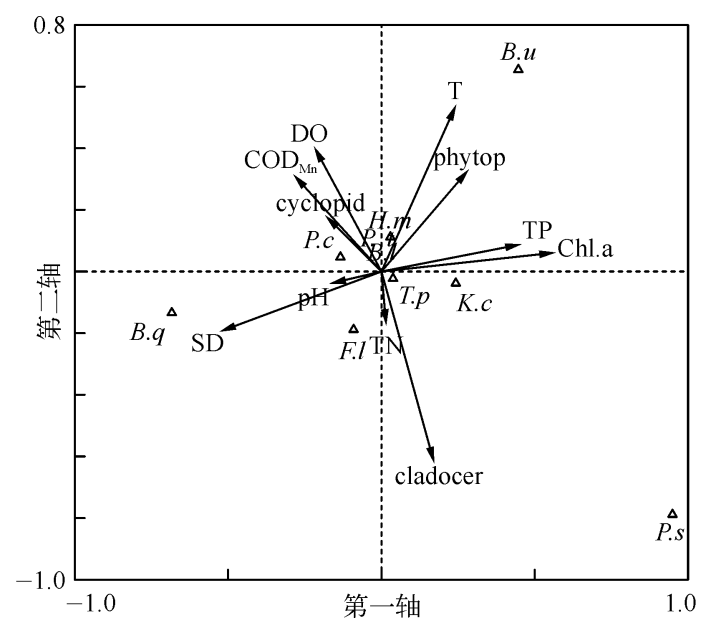

图 4 布伦托海轮虫物种和环境因子的 CCA 二维排 序图 (P.r: 针簇多肢轮虫, $F . l$ : 长三肢轮虫, $P . c$ : 扁 平泡轮虫, $H . m$ : 奇异六腕轮虫, $B . l$ : 矩形龟甲轮虫, $K . c$ : 螺形龟甲轮虫, T. $p$ : 暗小异尾轮虫, $B . q$ : 方形 臂尾轮虫, $B . u$ : 壸状臂尾轮虫, $P . s$ : 简单前翼轮虫, $\mathrm{DO}$ : 溶解氧, $\mathrm{T}$ : 温度, $\mathrm{SD}$ : 透明度, $\mathrm{pH}$ : 酸碱度, $\mathrm{TN}$ : 总 氮, $\mathrm{TP}$ : 总磷, $\mathrm{COD}_{\mathrm{Mn}}$ : 高锰酸钾指数, cladocer: 枝角 类生物量, cyclopid: 剑水虫生物量, phytop: 浮游植物 生物量)

Fig. 4 CCA biplot of species-environment of rotifers' commuinty in Lake Buluntuohai

(2) 与枝角类、剑水蚤的时空分布关系:2006 年秋,2006 年冬,轮虫与枝角类、剑水蚤的生物量呈相反的 趋势,2007 年春至 2007 年夏都呈一致的关系,2007 年秋呈相反的趋势,2007 年冬数据缺失,2008 年夏季轮 虫生物量与 2008 年春季相比略有上升, 而枝角类和剑水蚤的生物量从 2008 年春季至夏季呈上升的趋势, 即 趋势相一致( 图 7 和图 8). 中海子、73 km 小海子、骆驼脖子和大湖中轮虫生物量与枝角类、剑水蚤生物量都 呈相反的趋势, 其中剑水蚤与轮虫的相反趋势更明显( 图 9). 


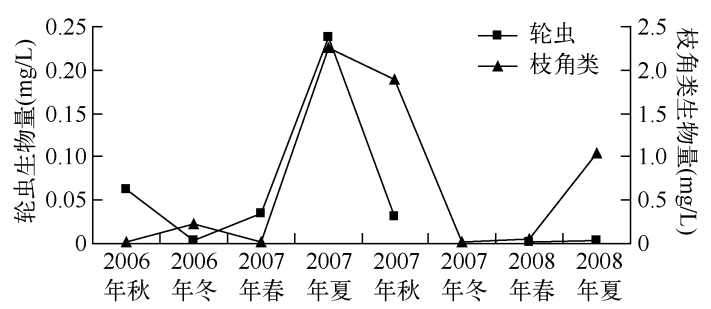

图 7 新疆布伦托海 2006 年秋至 2008 年夏轮虫 生物量与枝角类生物量的关系

Fig. 7 The relationship between biomass of cladocera and rotifer from autumn 2006 to summer 2008

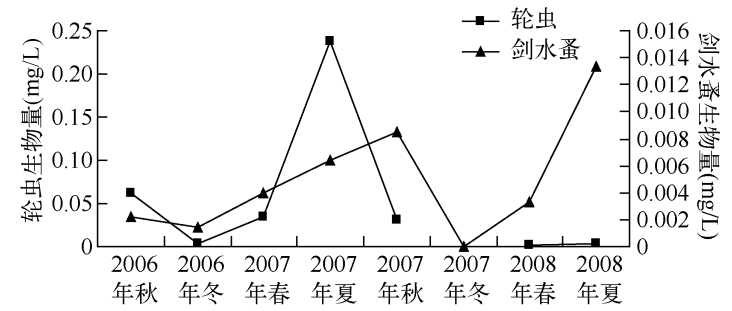

图 8 新疆布伦托海 2006 年秋至 2008 年夏轮虫 生物量与剑水蚤生物量的关系

Fig. 8 The relationship between biomass of cyclopida and rotifer from autumn 2006 to summer 2008

\section{3 讨论}

\section{1 布伦托海轮虫的时空分布特点及与环境因子的关系}

通过对布伦托海轮虫种类的调查研究共发现轮虫 30 种, 大湖的轮虫种类数多于湖湾 (骆驼脖子、 $73 \mathrm{~km}$ 小海子和中海子), 湖心区轮虫的种类数高于沿岸区, 其中长圆疮毛轮虫 (Synchaeta pectinata) 和矩形龟甲轮

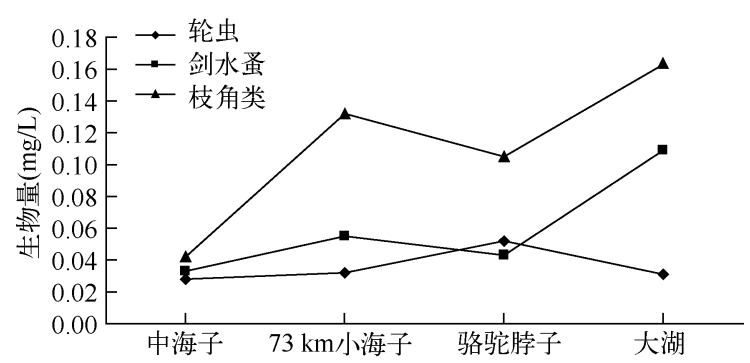

图 9 新疆布伦托海各湖区轮虫、枝角类、剑水蚤 的生物量的关系

Fig. 9 The relationship between biomass of rotifer、cladocera and cyclopida in every part of Lake Buluntuohai 虫 (Keratella quadrata) 属于浮游性轮虫种类, 在 湖心区大量出现. 这可能是轮虫的行为习惯导 致的; 当处于沿岸时, 它们的迁移的方向会引导 它们从沿岸移到湖心区, 以前大量的文献中也 常常用 “远离沿岸论” 来描述浮游动物通常不在 沿岸出现这个现象 ${ }^{[16]}$.

轮虫的密度和生物量在季节变化中形成单 高峰; 在空间变化中, 骆驼脖子达到最大, 湖心 区又高于沿岸区. 形成这一时空分布特点的因 素有很多, Devetter 指出影响轮虫结构最重要的 因素是总的物理和化学因素 (67.3\%), 其次为 竞争 ${ }^{[17]}$. 温度, 溶解氧和 $\mathrm{pH}$ 值都是影响轮虫密 度的主要物理化学因素 ${ }^{[18]}$. 布伦托海的 $\mathrm{pH}$ 值常

年相差不大, 而夏季的平均温度会达到 $26{ }^{\circ} \mathrm{C}$, 温度升高, 卵的发育时间缩短, 种群周转加快, 能够在短时间 内形成轮虫的密度高峰 ${ }^{[19]}$, 但在许多水体分层的富营养化湖泊中, 溶解氧的不足可以限制轮虫的生长 ${ }^{[20]}$. 本研究发现扁平泡轮虫 (Pompholyx complanata)、针簇多肢轮虫、矩形龟甲轮虫 (Keratella quadrata) 和奇异六 腕轮虫与温度、溶解氧呈正相关性.

布伦托海属于高原型湖泊, 湖里水草较少, 浮游植物为主要的第一生产力, 它是浮游动物的覀料生物. 在布伦托海中浮游植物生物量和轮虫的生物量随着季节的变化, 趋势相一致, 说明在季节变化中, 上行效应 对轮虫的生物量起着重要作用. 轮虫处于生态系统食物网中的第二营养级, 不仅受到浮游植物作为饵料生 物的上行效应影响, 还受到下行效应的影响. 水体浮游动物中, 轮虫和枝角类经常竞争相同的食物资源, 占 据相同的生态位. 大型枝角类能够通过争夺食物资源等方式抑制轮虫种群的增长, 甚至导致其消亡 ${ }^{[21]}$. 而桡 足类是轮虫的捕食者, 捕食轮虫的压力主要来自剑水虫 ${ }^{[22]}$. 布伦托海 2006 年秋至 2008 年夏季, 两年的秋冬 季节轮虫生物量和枝角类、剑水蚤生物量都呈负相关的关系, 在 2007 年春季和夏季呈正相关的关系, 而 2007 年春季至夏季浮游植物生物量迅速增加, 在 2007 年夏季形成最大值 ${ }^{[23]}$. 可以推断出在 2007 年春季至 夏季浮游植物对轮虫的上行效应占主导作用, 而在秋冬季节则是上行效应和下行效应共同作用.

由于生态系统空间的差异性, 导致影响轮虫丰度的主要环境因子在不同区域是不同的 ${ }^{[24]}$. 布伦托海各 
个湖区的 Chl. a 含量与轮虫的生物量趋势并不完全一致,而各个湖区轮虫的生物量与枝角类、剑水蚤的生物 量完全呈相反的趋势, 可以推断出下行效应可能对各个湖区轮虫的生物量影响起主导作用, 并且剑水蚤对 轮虫的捕食关系影响较大.

\section{2 外来种池沼公鱼对轮虫群落结构的影响}

国内外学者已从多方面证实了鱼类对大型浮游动物, 特别是对大型甲壳动物的捕食. 通常在同等能耗 下鱼类优先选择个体较大的浮游动物 ${ }^{[25]}$. 如果在同等大小的条件下, 鱼类首先摄食枝角类, 其次是哲水蚤, 最后才选食剑水虫 ${ }^{[26]} .1959-1988$ 年, 乌伦古湖年平均鱼总产量为 $2102 \mathrm{t}(\text { 表 1 })^{[27]}, 1986$ 年全湖轮虫的平 均密度为 349.1 ind. $/ \mathrm{L}^{[4]}, 1991$ 年引种移植和引水入湖后乌伦古湖布伦托海优势种由土著鱼类贝加尔雅罗 鱼转变为外来种池沼公鱼 ${ }^{[28]}$, 据统计, $1997-2001$ 年, 乌伦古湖年平均鱼总产量为 $3067 \mathrm{t}$, 其中池沼公鱼年 平均产量占 $40 \%$, 而 $2002-2006$ 年, 鱼平均总产量下降至 $2716 \mathrm{t}$, 但池沼公鱼年平均产量占 $60 \% .2006$ 年秋 至 2008 年夏, 全湖轮虫的平均密度下降至 74.1 ind. / L. 池中优质种池沼公鱼多以浮游动物为 食, 主要是轮虫、枝角类、桡足类 ${ }^{[29]}$, 这可能就是导 致十年后轮虫密度下降了 $78.8 \%$ 的原因. 周小玉等 对乌伦古湖池沼公鱼的食性研究中发现, 春季轮虫 个数在池沼公鱼的肠道中达到最大值, 夏季呈最低 值 未发表数据], 而池沼公鱼是集群活动的中上层 亚冷水性鱼类, 上限水温为 $29^{\circ} \mathrm{C}$, 产卵高峰期在 4 月初, 水温 $3-5{ }^{\circ} \mathrm{C}^{[30]}$, 这可能是导致池沼公鱼种群 数量在春季达到高峰, 从而使轮虫数量在夏季形成

表 1 乌伦古湖鱼类产量的历史变动

Tab. 1 Variation history of main economic fish in Lake Ulungur

\begin{tabular}{ccc}
\hline 年份 & 池沼公鱼年均产量 $(\mathrm{t})$ & 年均总产量 $(\mathrm{t})$ \\
\hline $1959-1988$ & 0 & 2102 \\
$1989-1996$ & 0 & 3237 \\
$1997-2001$ & 1226.8 & 3067 \\
$2002-2006$ & 1629.6 & 2716 \\
\hline
\end{tabular}
高峰的原因之一.

\section{4 参考文献}

[ 1 ] Saksena DN. Rotifers as indicators of water quality. Acta Hydrochimica et Hydrobiologica, 1987, 15(5) : 481-485.

[2] 李共国, 虞左明. 千岛湖轮虫群落结构及水质生态学评价. 湖泊科学, 2003, 15(2) : 169-175.

[3] 陈立婧, 顾 静, 彭自然等. 滆湖轮虫群落结构与水质生态学评价. 动物学杂志, 2008, 43(3): 7-16.

[ 4] 陈伟民, 周万平, 郭晓鸣. 新疆乌伦古湖的浮游生物. 中国科学院南京地理与湖泊研究所集刊, 1988, 5: 59-69.

[5] 任慕莲. 新疆吉力湖的渔业. 哈尔滨: 黑龙江科学技术出版社, 1990:214-218.

[6]叶尚明, 苏德学, 刘 栓等. 新疆乌伦古湖水生生物资源调查研究. 水利渔业, 2004, 24(2): 51-53.

[ 7 ] 董 做, 江 敏, 刘其根等. 乌伦古湖水质及营养水平调查. 上海水产大学学报, 2008, 17(5): 564-569.

［8］ KI/T91 - 2002, 地表水和污水监测技术规范. 国家环境保护总局, 2002.

[ 9 ] 章宗涉, 黄祥飞. 淡水浮游生物研究方法. 北京: 科学出版社, 1991: 358-388.

[10] Koste W. Rotatoria. Die Rädertiere Mitteleuropas. Berlin: Gebrüder Borntraeger, 1978: 673.

[11] 王家楫. 中国淡水轮虫志. 北京: 科学出版社, 1961.

[12] Sladack V. Rotifers as indicators of water quality. Hydrobiology, 1983, 100 : 169-2021.

[13］ GB3838-2002, 地表水环境质量标准. 国家环境保护总局, 2002.

[14] 彭文涁, 刘红瑛, 陈敬员. 两种分光光度法测定浮游植物叶绿素 $\mathrm{a}$ 的比对试验. 黄石高等专科学校学报, 2002, $18(3)$ : 34-36.

[15] 徐兆礼, 陈亚㫿. 东黄海秋季浮游动物优势种聚集强度与鲐鱼渔场的关系. 生态学报, 1989, 8(4): 13-15.

[16] Preißler K. Do Rotifers show “avoidance of the shore”? Oecologia, 1977, 27(3) : 253-260.

[17] Devetter M. Influence of environmental factors on the rotifer assemblage in an artificial lake. Hydrobiologia, 1998, 387/ 388 : $171-178$.

[18] Hofmann W. The influence of abiotic environmental factors on population dynamics in planktonic rotifers. Arch Hydrobiol Beih Ergebn Limnol, 1977,8 : 77-83.

[19] 王 庆, 刘丽君, 杨宇峰. 南方某水库轮虫群落结构及其对环境因子的响应. 生态学报, 2010, 30(13): 3385-3395.

[20] Herzig A. The analysis of planktonic rotifer populations: A pleafor long-term investigations. Hydrobiologia, 1987, 147: 
163-180.

[21] Gilbert JJ. Suppression of rotifer population by Daphnia: eview of the evidence the mechaniss and the effects on zooplankton community structure. Limnology and Oceanography, 1988, 33: 1286-1303.

[22] 任晶晶, 林秋奇, 韩博平. 热带水库敞水区轮虫种类组成与数量结构一一基于海南 7 座典型水库的分析. 湖泊科 学, 2010, 22(2) : 272-280.

[23] 刘 宇, 沈建忠, 李鸿等. 新疆乌伦古湖浮游植物群落结构. 湖泊科学, 2009, 21(6) : 855-864.

[24] 卢亚芳, 黄永春, 周立红. 杏林湾水库环境因子对浮游轮虫密度的影响. 上海水产大学学报, 2002, 11 (3): 225-229.

[25] Hall DJ, Threlkeld ST, Burns CW. The size-efficiency hypothesis and the size structure of zooplankton communities. Annual Review of Ecology and Systemutics, 1976, 7 : 177-208.

[26] Brooks JL. Eutrophication and changes in the composition of the zooplankton. In: Eutrophication: causes, consequences, correctives. National Academy of Sciences, 1969: 236-255.

[27] 唐富江. 新疆乌伦古湖外来鱼类对河鲈人侵机制的研究 [学位论文]. 重庆: 西南大学, 2008.

[28］阿达可白克. 可尔江, 苏德学, 杨 艳等. 乌伦古湖鱼类资源现状及保护与开发对策. 上海水产大学学报, 2006, 15(3) : 309-314.

[29］张仁福, 陈利疆, 赵卫军等. 水库移植池沼公鱼试验. 淡水渔业, 2001, 31(1): 26-27.

[30］杨天祥, 孙 健, 汪兆生等. 柴河水库池沼公鱼栖息规律的调查. 水利渔业, 1998, (6): 31-32. 